\title{
Discourse Competence Of Interpreters: Interdisciplinary Approach
}

\author{
E. Yu. Moshchanskaya \\ Department of Foreign Languages, Linguistics and Translation \\ Perm National Research Technical University, \\ Perm, Russia \\ emosch@mail.ru, mosch@yandex.ru
}

\begin{abstract}
Theoretical analysis showed that the notion of a discourse competence has many interpretations. However, the following common features of this concept should be highlighted: knowledge of rhetorical and information structure types of statements, specifics of various text genres, ability to create a coherent utterance in accordance with communication scenarios, including adequate choice of a particular communication style and register. Discourse competence of the interpreter includes receptive and productive skills required in interpreting of an oral discourse, taking into account all its contextual components and in accordance with the norms of interacting cultures, ability to identify important and significant units of an utterance. The discourse competence is formed in the study of many practical and theoretical disciplines, so in this paper an interdisciplinary approach to the development of this competence was used.
\end{abstract}

Keywords-discourse competence, interdisciplinary approach, interpreter's discourse competence

The development of discourse study within cognitive linguistics led to the formation of a discursive approach, which is implemented in various sciences. The focus of this approach is to form the discourse competences (hereinafter referred to as DC). The discourse competence as a subject was introduced into the structure of the communicative competences in the 1990s of the past century. Different authors offer various understanding of DC content. Thus, M. Canale and M. Swain distinguish three major aspects of the communicative competence: grammatical, sociolinguistic and strategic, whereas the discourse competence (ability to create coherent oral or written texts of different genres and in different situations, knowledge of cohesion and coherence rules) is an integral part of the sociolinguistic competence [1].

Lyle F. Bachmann, a representative of text linguistics, considers the discourse competence (or text competence) as part of the organizational competence, which in turn, constitutes a language competence. The latter one includes knowledge and ability to apply syntactic cohesion, semantic coherence, the rhetorical structure of texts (a description, a statement, a story, an instruction), the information structure (theme/rheme; known/new), and the conversation structure (for example, change of a speaker, maxims of conversation, etc.). According to L. Bachmann, the discourse competence covers the ability to create texts taking into account their rhetorical structure, thematic-rhematic articulation, maxims of conversation [2].

Authors of the Common-European Competences for Language Skills place discourse competence alongside with functional and structural components of a communicative competence, and interpret it as "abilities to put sentences into a single coherent text, taking into account topic/focus, known/new information, natural sequence of actions, causeeffect relationships, topic, coherence and integrity; logic, style and register of communication, impact on the interlocutor, Grice's cooperative principles" [3].

Summarizing the above-mentioned information, one may conclude that the concept of the discourse competence, as well as the concept of a discourse in general, can have different interpretations and is included into various components of the communicative competence. At the same time, it is possible to identify common features of this concept: knowledge of rhetorical and information structure within types of utterance, specifics of various text genres, ability to create a coherent statement within a communication situation, including the ability to properly choose a style and register of communication.

The analysis of specialist's DC presented in domestic study revealed that DC is understood as the "ability to perceive and generate spoken messages within a particular pragmatical context" [4] and as the "ability to use professional vocabulary, which makes it possible to adequately clothe communicative intensions and strategies of their achievement into a language, to distinguish communicative intensions of foreign partners, as well as the ability to use norms of speaking etiquette and social behavior in formal and informal professional situations" [5]. A master's DC implies the "understanding of specific rules, norms and stereotypes of discursive behavior accepted and shared by members of the global scientific community, as well as efficient ability to generate and perceive complete, coherent scientific texts of various genres and rhetorical types" [6]. Thus, the discourse competence of a specialist is formed within the professional sphere and implies knowledge of behavioral norms and stereotypes in a particular professional situation, understanding of various text genres, receptive and productive abilities, including the ability to make an utterance corresponding to a particular situation of communication. 
The definition of interpreter's discourse competence uses the same notions, however there are aspects reflecting interpreting/translation activity, existence of foreign and sociocultural elements of an interpreting context. N.N. Gavrilenko includes the discourse competence into a special component of the professional competence of an interpreter and defines it as the "readiness and ability to understand various genres of a foreign-language special discourse and to create the target text according to the author's plan, a communicative situation and sociocultural norms of communication accepted in Russia" [7, 8]. N.N. Gavrilenko presents the concept of the discourse competence in translation within the academic program Translation in the field of professional communication", where translation takes place in one direction only: from the foreign into Russian language. Another interesting aspect is interpreting (oral translation) when the interpreter operates at least two languages and cultures. In this respect, there is a need to reflect the bilingual and bicultural profile of DC definition. The discourse competence of an interpreter is understood as readiness and ability to perceive and understand oral and speaking discourse of the subjects of communication, belonging to different cultures, thus combining all components (speaking, nonverbal, personal, genre, communicative, interactive, sociocultural, eventive) to identify the main thought, based on context, and to transmit the message according to the situation of communication, its national and cultural features, structuring, realization (choice of appropriate linguistic and extralinguistic means within a genre, functional style and register of communication) provided it is adjusted to the receiving culture [9].

The subject of this study focuses on the development of discourse competences of a bachelor of linguistics in Translation and Theory of Translation. The paper considers requirements of the Federal State Educational Standard of Higher Education for 035700 Linguistics (bachelor's degree). The standard qualifies the discourse competence as part of professional competences in the field of practical professional activity and codes this competence as PK-3. The competence is formulated as follows: a graduate knows and applies basic discursive methods of communication taking into account peculiar features of a current communicative context (time, place, objectives and conditions of interaction) [10].

The DC of a bachelor of translation requires knowledge of various spheres of science, which is caused by complex nature of a discourse itself and features of this competence. The interpreter's DC is formed within different disciplines of Translation and Theory of Translation, which makes this competence unique. Other practical disciplines covering this concept include the following: Oral Speech Practice, Conversation Practice, Speaking and Listening in Interpreting, Oral Consecutive Interpreting of the First and Second Language, the Russian Language and Culture of Speech, Culture of Nonverbal Behavior in Oral Consecutive Interpreting, and such theoretical disciplines as: Stylistics, Introduction to the Theory of Cross-Cultural Communication, Translation Theory. Hence, it is suggested to promote the interdisciplinary approach to specialists' and interpreters' DCs, which is understood as the method of discourse competence development, thus allowing separate components to be mastered through various intercultural and professional disciplines. It should be noted that the interpreter's DC is mastered in two stages: the first stage focuses on foreignlanguage DC of a specialist in the field of cross-cultural communication, while the second stage centers around the development of interpreter's DC as such.

Below there are the main components of interpreter's DC development. The knowledge component includes the following elements:

- Knowledge of basic cognitive models of professional discourse.

- Knowledge of typical communicative situations, contextual cliches and gestures, rules, norms and stereotypes of communicative behavior of subjects of communication and an interpreter in such situations.

- Knowledge of the main genres of oral professional discourse, as well as features of their composition and linguistic realization; specifics of their interpreting.

- Knowledge of the rhetorical structure of compositional and functional types of an utterance and specifics of their interpreting through consecutive interpreting.

- Knowledge of functional styles and registers of communication and their correlation with official, semiofficial and daily communicative situations.

- Knowledge of the information structure of an utterance and its recording during note-taking in consecutive interpreting.

- Knowledge of primary values of both interacting cultures.

- Knowledge of main strategies and tactics of professional discourse.

- Knowledge of specifics of interaction between two cultures, ethical standards and communicative (verbal, nonverbal, ritual) behavior in typical communicative situations and ability to put this knowledge into corresponding practice.

- Knowledge of historical context of interaction at the level of countries, organizations and direct participants of communication.

Thus, the interpreter's DC includes the following six groups of integrated abilities:

1) abilities associated with perception, understanding and transmission of a creolised utterance meaning, including a context-based utterance. This also includes abilities related to decoding of a paralinguistic and nonverbal component of an oral discourse (ability to perceive and understand, as well as to efficiently apply paralinguistic means of communication and nonverbal behavior in order to add and emphasize a thought expressed through verbal means of communication, to create a favorable atmosphere and positive image of partners);

2) abilities associated with perception, understanding and transmission of an utterance information structure, including that based on note-taking and PPT slides; 
3) abilities associated with genre and text specifics of an utterance (perception, understanding and transmission of coherent, logical, contextual oral statements of different genres with adequate tonality, register and style of an utterance);

4) abilities associated with perception, understanding and transmission of the rhetorical structure of various compositional and functional types of an utterance;

5) abilities reflecting specifics of communicative behavior in typical communicative situations: ability to identify, to transmit and, if necessary, to adjust ethical standards, ritual forms of communication and behavior (verbal and nonverbal) to a particular culture; knowledge and ability to use contextual cliches and gestures;

6) abilities of communicative interaction, including emotional and empathic interactions: recognition and transmission of intensions and dominating strategy of speaking and interaction within a communicative situation; ability to control emotions and demonstrate empathy towards interacting parties, ability to work with information throughout interaction, including the ability to request the necessary information in the course of interpreting, etc.

The discourse competence is considered an integrative phenomenon, which unites the following subcompetences within the uniform act of communication:

- Text competence: knowledge, skills and abilities to perceive, understand and transmit an utterance taking into account rules of cohesion, coherence and logic;

- Genre competence: knowledge, skills and abilities to perceive, understand and transmit compositional structures, functional and linguistic features of oral genres, sequence of communicative acts in their structure;

- Extralinguistic competence: knowledge, skills and abilities to perceive, understand and transmit the meaning of an utterance within extralinguistic context;

- Sociolinguistic and sociocultural competences: knowledge, skills and abilities to perceive, understand and consider a social context, adequate perception and understanding of culture-specific language, nonverbal and extralinguistic features of communicative behavior of native speakers, as well as the ability to comment and explain cultural aspects in interpreting; ability to demonstrate communicative behavior complying with ethical standards of interacting cultures;

- Thesaurus competence: declarative, procedural knowledge and subject matter expertise in the field of professional communication, as well as willingness and ability to gain the necessary knowledge, including the ability to find a proper way of interpreting certain terms;

- Existential competence: ability to communicate and interact with the subjects of communication from different cultures.

Let us consider peculiarities of DC development within practical disciplines for 035700 Linguistics (bachelor's degree) in Translation and Theory of Translation. This task covered the analysis of available programs of practical disciplines following the modernization of some learning objectives and the description of a disciplinary component within the discourse competence.

The objective of Oral Speech Practice is to develop "foreign-language speech competences as an intergral part of speech culture and professional culture of future interpreters, thus ensuring sound listening comprehension skills through dialogues and monologues in a foreign language, ability to conduct a dialogue with partners, to make monological statements in various communicative situations of everyday life and professional activity" [11]. This discipline implies the development of some DC components focused on the implementation of communicative intentions within context thus complying with logic, coherence, clarity, semantic and structural comprehensibility, language norm, stylistics and sociocultural aspects. Throughout their study, students will master basic compositional and speaking forms: description, narration, argumentative reasoning and denial reasoning (arguments, comparisons, estimates) and their application in such speech genres as presentations, lectures, reports, roundtable discussions, interviews, conversations. These communicative genres are implemented in situations of social and public communication: talk shows, presentations, roundtable discussions, conferences. Among dominating functional styles, there are colloquial, literary, and official styles.

Conversation Practice is aimed to develop and improve professional communication culture implying the ability to use a foreign language as means of foreign cross-cultural communication for specific purposes (namely, in economic discourse) taking into account typical situations of interaction and cultural behavior. Throughout this discipline in particular, students master their skills and abilities of professional crosscultural communication in a foreign language that contribute to social and professional contacts between representatives of different cultures [12]. Besides, students improve their abilities to use basic compositional and speech forms and learn to make statements, comments, explanations, proofs, opinions, and arguments. Various authentic situations of communication, role-plays and business games are aimed to master fundamentals of communicative etiquette. Official business communication is the main functional style within this discipline. However, students also learn such monologic genres as self-presentation and sales or company presentation, and such dialogic genres as sales negotiations, employment interviews, presentation of information, company, product, and conference talks.

Oral Consecutive Interpreting of the First and Second Language is aimed to develop students' understanding of basic and special professional competences of an interpreter, readiness for mediation and mediative activity in the field of professional and everyday conversations to ensure information exchange and interaction between representatives of different countries and cultures [13]. Throughout this discipline, students master various skills and abilities, namely judgment, understanding and transmission of functional dominating ideas of various speech genres, compositional and speech forms, etiquette formulas and patterns of communicative behavior 
accepted in a particular culture within a specific situation of semi-official and official communication. Future interpreters acquire skills to transmit the following genres: welcoming speeches, conference reports, toasts, production visits, jokes, business conversations, and negotiations. Official business communication combined with colloquial style is the main functional style within this discipline. Various authentic situations of interpreting, role-plays and business games foster the development of interpreters' behavior. Students also learn to interpret at such discursive events as business visits (meeting at airport, hotel, meeting with the governor, exchange of contacts, meeting at a restaurant, sightseeing tour); trade fairs (round-table discussions, negotiations); conferences on economy or ecology.

The objective of Speaking and Listening in Interpreting is to develop listening and speaking skills and abilities to comply with interpreter's ethical standards of verbal and nonverbal behavior thus ensuring efficiency of information exchange and interaction between representatives of different countries and cultures in various communication domains [14]. The disciplinary part of the discourse competence is presented as the ability to perceive and understand an utterance in terms of its transmission to participants of communication and to generate a coherent statement thus preserving functionality of speech genres, ethical standards, and ritual aspects of nonverbal behavior with respect to interpreter's behavioral standards applicable for a particular sutuation. Listening comprehension implies perception and detailed understanding of the entire information, consideration of all components of a discursive context, bilingual and bicultural actions of an interpreter when the latter one is focused on the subject matter discussed between participants of a conversation. Interpreter's speaking skills are defined as the ability to transmit monological statements of participants into another language thus preserving its functional and genre aspects and comply with ritual forms of verbal and nonverbal behavior with respect to interpreter's behavioral standards applicable for a particular sutuation. These genres are used to develop interpreter's listening skills: audio and video reports, briefings, talk shows. Development of interpreter's speaking skills is ensured through conference talks, round table discussions, master classes, excursions, and negotiations.

The objective of Culture of Nonverbal Behavior in Consecutive Interpreting is to develop the interpreter's culture of nonverbal behavior necessary for adequate professional interpreting within various communicative situations [15]. The disciplinary aspect of this competence is understood as the ability to perceive and understand nonverbal behavior and paralinguistic elements of an utterance as a required element of communicative behavior, to consider the perceived information in interpreting, to keep logical and emotional (if necessary) components of a discourse when using the corresponding means of nonverbal communication, to interpret in compliance with behavioral standards of the interacting cultures, situation and standards of interpreter's ethical behavior. Throughout this discipline, students acquire paralinguistic means of communication and patterns of nonverbal behavior typical for such situations as official visits, presentations, negotiations, excursions, training sessions, conversations between native and foreign cultures, role-plays and business games. The analysis shows that when mastering various practical disciplines, students expand their knowledge of compositional and speech forms, oral genres and communicative situations, develop interpreter's abilities and character traits.

E.A. Aristova, E.Y. Moshchanskaya, O.V. Protopopova in their paper Training Bachelors of Translation and Interpreting to Work in the Excursion Context: an Interdisciplinary Approach give an example of the interdisciplinary approach to development of interpreter's discourse competence in the excursion context. Within the Russian Language and Culture of Speech, students master text coherence, integrity, dialogueness within a monological statement (excursion) in the native language. Within the Practical Phonetics and Voice Culture in the First Foreign Language, students develop their abilities of the guide's voice culture in a foreign language. The objective of the Culture of Nonverbal Behavior in Oral Consecutive Interpreting is to master nonverbal means of communication in a particular situation, and the Interpreting in the First Foreign Language, which is taught in parallel, is focused on development of interpreter's discourse competence in the excursion context.

In general, it should be noted that there are both advantages and disadvantages in the interdisciplinary approach to DC development. The advantage is that every discipline contributes to either development or improvement of a certain element of the discourse competence through adequate speech genres and typical role-plays thus ensuring the integrity of communication areas, speech genres and situations. The disadvantages include lack of uniform monitoring of interpreter's DC level development and insufficient academic hours, which often does not foster the full development of the discourse competence.

It is known that any competence implies some practical experience, and hence the Department of Foreign Languages, Linguistics and Translation of Perm National Research Technical University organized the Interpreter's Club where students can master their skills of consecutive interpretating through different simulation scenarios. The club allows solving the following pedagogical and educational tasks:

- introduction to mentality and culture of Germany, Austria, England, America and other countries,

- understanding particular professional features of various public activities;

- improvement of skills and abilities within information and communicative competences (search for information on the subject of speaking, on the subject of utterance, communication with the native speaker about the subject of utterance, ability to request relevant information in interpreting);

- improvement of skills and abilities of consecutive interpreting in various communicative situations: presentations, round-table discussions, interviews, excursions;

- improvement of skills and abilities of judgment, understanding and trasnmission of messages having different 
genres into the target language taking into account interactions between different cultures;

- improvement of the rhetorical competence of future interpreters;

- development of skills and abilities of interaction and team work with other interpreters proficient in other languages;

- improvement of skills and abilities of interpreter's nonverbal behavior;

- development of abilities to cope with stress and emotions.

Students' survey showed that the Interpreter's Club is an effective form of training of future translators for their professional activity, which further improves discourse and professional competences of an interpreter.

In conclusion it should be noted that the development of the discourse competence of future interpreters predetermines the need for the interdisciplinary approach and the monitoring of its further implementation. With regard to didactics, it is important to consider the following components of a curriculum: 1) knowledge of a concept of discourse and its types; 2) use of authentic video records in training; 3) simulation of discursive events, communicative situations and interpreting scenarios; 4) knowledge of genres of oral discourse; 5) knowledge of a component structure of extralinguistic context of communication and its consideration in understanding and extracting the main idea of an utterance.

\section{References}

[1] M. Canale, M. Swain, "Theoretical bases of communicative approaches to second language teaching and testing," Applied Linguistics, vol. 1 (11), pp. 1-47, 1980 .
[2] Lyle F. Bachmann, Fundamental Concepts in Language Testing, Oxford: Oxford University Press. 1990, Didaktisches Lexikon [Internetresourse] URL:http://www.oldenbourg.de/osv/zeitschriften/fsu/didaktischeslexiko n/pfu_02_13_didaktisch.pdf

[3] Common-European competences for second language skills: studying, teaching, assessment. MSLU, 2003.

[4] A. P. Rudenko, "Individual approach for developing students' discursive competence in the process of teaching a foreign language in high school," dis. ... cand. Sc., Veliky Novgorod, 2007, pp. 28.

[5] N.A. Baranova, "Bases of students' discursive competence development in the process of teaching a profession-oriented foreign-language communication," dis. ... cand. Sc. Saint-Petersburg, 2008. pp.244.

[6] T.V. Mordovina, "Teaching written scientific discourse for Master's degree students: as exemplified in the scientific article," English language: dis. abstr., cand. Sc. Tambov, 2013, pp.24.

[7] N.N.Gavrilenko, Integrative model of translation studying [Electronic resource] URL: http://nng.leaderuk.tmweb.EN/concept/ (accessed date: 03.24.2015).

[8] N.N. Gavrilenko, Teaching translation in the field of professional communication: Monograph, M.: PFUR, 2008, pp.175.

[9] E.Y. Moshchanskaya, Interpreter's discursive competence as an object of development, Teaching foreign languages in the context of modern educational paradigm (German), Collective monograph, Ex. Ed. S.S. Gabdullinю Ufa: Aeterna, pp. 69-131.

[10] V.V. Zvyagina, N.V. Chudinova, E.Y. Moshchanskaya, N.G. Pogorelaya, First foreign language oral speech practice. Perm: PNRPU, 2014 , pp.32.

[11] T.A. Goreva, E.Y. Moshchanskaya, M.P. Kovalenko and I.K. Fedorova, First foreign language conversation practice, Perm: PNRPU, 2014. pp. 32.

[12] E.V.Alikina, I.A. Avkhacheva, E.Y.Moshchanskaya, First foreign language interpreting, Perm: PNRPU, 2014. pp 32.

[13] I.A. Avchacheva., E.A Rutskaya, E.A. Alikina, Speaking and listening comprehension in the process of first foreign language consecutive interpretation. Perm: PNRPU, 2014. pp. 32.

[14] E.Y. Moshchanskya, Culture of the first foreign language non-verbal behaviou. Perm: PNRPU, 2014. pp. 34.

[15] E.A. Aristova, E.Y. Moshchanskaya, O.V. Protopopova, "Training bachelors of Translation and Interpreting to work in the excursion context: an interdisciplinary approach," Pedagogical education in Russia, No. 8, pp. 6-12, 2015. 